\title{
In-flight folding wingtip system: inspiration from the XB-70 Valkyrie
}

\author{
Gaétan Dussart* and Mudassir Lone ${ }^{\dagger}$ \\ Cranfield University, Dynamic Simulation and Control Group \\ Cranfield, Bedfordshire, MK43 OAL, United Kingdom \\ Ciaran O’Rourke ${ }^{\ddagger}$ and Thomas Wilson ${ }^{\S}$ \\ Airbus Operations Ltd \\ Filton, Bristol, BS34 7PA, United Kingdom
}

\begin{abstract}
Wingtip folding can be used to extend aircraft wingspan, allowing designers to take advantage of reduced induced drag whilst respecting ground operational limitations. Such devices can also be used in-flight for a variety of other benefits including load alleviation and flight control. The majority of in-flight folding research takes inspiration in past developments made on the XB-70 Valkyrie, which used the folding devices for stability and lift performance benefits. In this paper, the authors investigate the capabilities of the folding wingtip system and potential scaling to large civil aircraft. Manufacturing details are used to size the actuators whilst the aerodynamic loading acting on the wingtip hinges is found from flight test results. Dimensions and aerodynamic loading at cruise of a set of conventional civil aircraft wing are used to evaluate the scaling potential of the system for controlled in-flight folding. An estimate of the weight penalty due to the folding device is also given and compared to structural weight savings on the XB-70. The results presented herein help in the evaluation of conventional actuator limits for in-flight folding using arguably the most inspiring military example of wingtip folding so far.
\end{abstract}

\section{Project Motivation}

$\mathbf{T}^{\mathrm{T}}$ is well known that a well designed High Aspect Ratio Wings (HARW) will have better aerodynamic performances 1 than currently used conventional swept wings. But ground infrastructures and inherent limitations on aircraft wing span have always been significant parameters in aircraft design and wing shape and geometry. Ground folding was historically proven as an effective way to bypass dimensional requirements to operate carrier-based aircraft, in both fixed and rotary winged vehicles. As only a limited fixed space can be allocated per aircraft to maintain fleet size and operational levels, engineers are forced to include these ground morphing devices to maintain vehicle performance whilst ensuring the aircraft meet market demands. Facing similar concerns, and undoubtedly inspired by these systems, aircraft designers are now considering the implementation of similar span reduction strategies on large civil aircraft. Aircraft size limitations, dictated by airport infrastructures, could be virtually exceeded by implementing similar ground fold systems. This would allow next generation HARW aircraft, examples of which can be found in the NASA Sugar HARW concept [1] or Boeing 777-X, to be operated within the same infrastructures as their predecessors. This leads to limited additional infrastructure overhaul and increases in operational costs to airports and airlines when replacing the outdated and less profitable fleet. Nonetheless, the folding device in turn brings a number of additional complications in design, maintenance, operational complexity, and an obvious weight (and therefore performance) penalty from the device itself, which can be evaluated using the Breguet range formulation [2].

Of course, the principle of changing the aircraft shape in-flight, or morphing, is hardly new. It can be traced back to the first flying machines, such as those sketched by M. Ader in his Aole aircraft concepts from 1890 [3], pictured in Fig 1 . or the early powered glider flights of the Wright brothers in 1903. The first would have relied on deployable bat-like wing structures to adapt to various mission requirements, whilst the latter efficiently used wing warping as a mean for aircraft control. But as human flight made its first steps in history, aircraft development became irrevocably linked to military applications. Stronger, faster and more reliable airframes were soon required for military applications. This

\footnotetext{
*PhD candidate, Dynamic Simulation and Control Group, g.x.dussart@cranfield.ac.uk

†Lecturer, Dynamic Simulation and Control Group, m.m.lone@cranfield.ac.uk

${ }^{\ddagger}$ R\&T Project Leader for Wing Architecture, ciaran.orourke@airbus.com

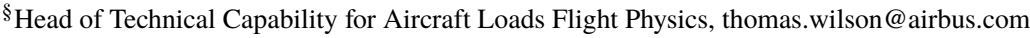


led to metallic airframes and hinged control surfaces to cope with increased loads, speeds and structural requirements. Effectively, continuous wing warping and other attempts at unconventional morphing quickly became marginal in aircraft development, though a number of past flown examples can be found in the literature [3-6]. It is worthy to note that the most successful morphing aircraft so far have been those with variable sweep, with a number of military examples, as it allows for significant performance changes and flight envelope extension. In the field of dihedral folding wingtips, the most notable past flown example lies in the XB-70 Valkyrie, a large supersonic strategic bomber developed in the 1970's, pictured in Fig 2. The term folding is used here, as the relative simplicity of the hinged control surface movement and control, however large, could arguably put it a bit shy of the unofficial requirements to qualify as a morphing aircraft [4, 6].

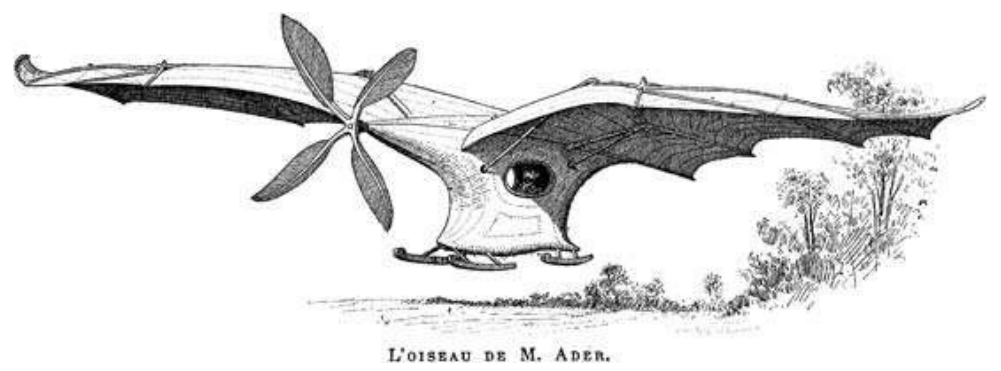

Fig. 1 A sketch of the Eole aircraft, with a bat-like deployable wing.

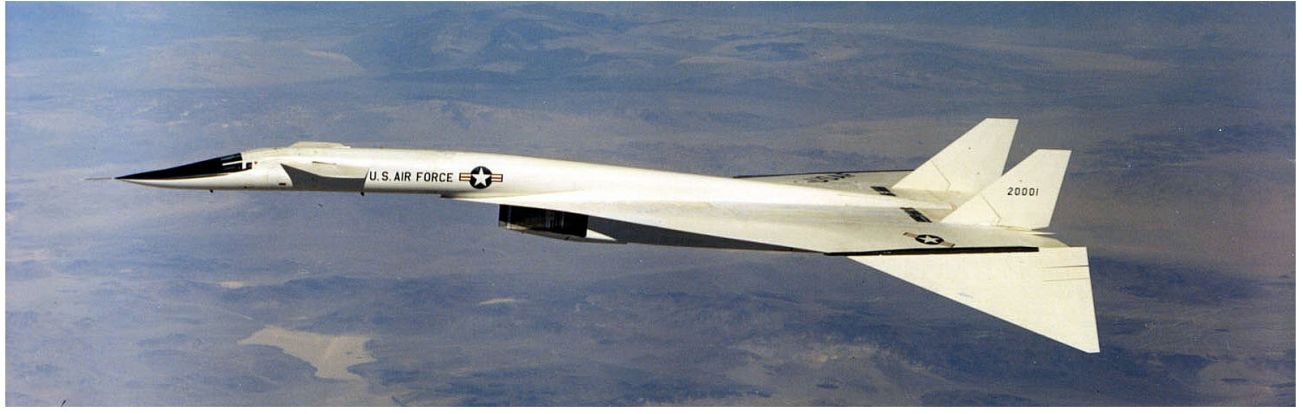

Fig. 2 The XB-70 AV-1 in flight, with wingtips folded $25^{\circ}$ downward at low supersonic speeds.

Morphing aircraft research in the academic and industrial worlds are currently exploring a number of innovative and complex solutions in an effort to reduce weight and increase the performances of morphing devices. Some rely on compliance structures [7-10] to replace heavy and bulky hinges. Conventional control actuators are also replaced by more power dense actuators such as Shape Memory Alloys (SMA) or Polymers (SMP) [11]. The capability of morphing or smart skins [12] to ensure aerodynamic shape continuity throughout the aircraft morphing spectrum has also received significant interest. Mathematical investigations for complete mission analysis and flight controls were also made [13-16] to highlight the benefits of multi-mission continuous morphing vehicles through simulation, but a number of daunting tasks remains to be tackled, specifically in actuation, systems and structural requirements. In the recent years, a wide variety of working examples have been set forward, using a combination of all or part of the above. This includes a multi-mission Z-fold aircraft concept model and wind-tunnel demonstrator [17] or a mission adaptive compliant flap, from development to setup and testing [18]. Bourdin et al. [19], with a more conventional actuation approach, developed an experimental wind tunnel model for aircraft control using folding wintips, highlighting their potential for longitudinal control when used in tandem. A corrugated skin concept for similar actuated wingtips was also investigated [20]. A demonstrator of new smart actuation and skin was also made for a wing profile camber morphing [21]. Lastly, a sub-scaled demonstrator was flown recently as part of the Spanwise Adaptive Wing (SAW) project [22, 23]. The NASA led tests highlighted the potential for subsonic commercial applications of in-flight dihedral wingtip morphing using SMAs, including increased fuel-efficiency, controllability and possibility to reduce tail size as deflected wingtips offered enhanced directional stability. In the last few years, a joint academic and industrial research project between Cranfield University, the University of Bristol and Airbus Group, has aimed at evaluating potential benefits and feasibility of implementing in-flight dihedral folding wingtips on large civil aircraft, rather than simple ground fold devices. Mathematical models of a flared folding wingtip device fitted on a large civil aircraft have led to the assessment 
of the gust load alleviation capabilities [24] and impact on roll dynamics of the aircraft [25]. Wind tunnel tests have also highlighted the loads alleviation potential of the wingtip on a sub-scale model [26]. A summary of the findings around the use of folding hinged wingtips [27] was also published as part of the same project. These past investigations have provided a wide spectrum of encouraging results for in-flight wingtip folding applications on large civil aircraft.

But such applications and industrial development of morphing devices or structures is still relatively juvenile, with challenging and tedious engineering and certification tasks yet to be dealt with. A clear lack of research and results on full-scale actuation options for a folding wingtip device, a key system design criteria, has been identified. Concerns regarding the scalability of the technologies mentioned previously to large civil aircraft flight, particularly compliance structures, SMAs and SMPs were raised due to the dependency on weight, size and frequency of morphing required, maintenance and complexity. Therefore, it remained unclear whether it would be plausible to rely on conventional actuation strategies (hydraulic or electric) for short term applications given the spatial and performance requirements, or if further development in actuation and morphing technologies were required to design feasible systems.

Hence, to help develop future aircraft technologies, the authors have looked at past developments and applications in the field of folding wingtips for inspiration, focusing on the XB-70 Valkyrie. Arguably the most iconic example of folding wingtip capable vehicle, it boasted the largest moving lifting surfaces ever flown and provides a good insight on the actuator and systems requirement for wingtip folding. A quick overview of the iconic XB-70 supersonic bomber is given in Section $\Pi$, partly to identify key motivations and benefits in the implementation of the folding wingtips. A review of the gathered and derived data regarding the actuation system is given in Section III specifically in terms of size, weight and actuation capability. With such results in hand, a comparison against spatial and loads requirements of a set of conventional tubular swept wing aircraft wings is made in Section IV to assess the scalability of the system to civil applications. The paper concludes with a general discussion on the applicability of these results and impact on the flared folding wingtip design considered for loads alleviation [24-27].

\section{Historic overview of the iconic XB-70}

When investigating past developments in the field of in-flight morphing, one would be hard pressed not to find mentions of the iconic XB-70 Valkyrie supersonic aircraft, pictured in both Fig. 3 and Fig 4a [28]. The aircraft, which first flew in 1964, ten years after its inception by the United States Air Force [28, 29], was designed as a strategic supersonic bomber for the Strategic Air Command. The conception obviously constituted an incredible challenge as it was intended for high altitude flights at three times the speed of sound, and required ground-breaking developments in many aspects of aerospace vehicle design.

Clever aerodynamic engineering and the use of an unconventional (at the time) canard design feature allowed for adequate aerodynamic performances to be achieved throughout the flight envelope, from landing speeds to Mach 3. A hinged nose cone was also used, which, when lowered, would give the pilots sufficient visibility during low altitude subsonic flights. At higher speeds, the upper panel of the nose cone would then realign with the fuselage to restore better aerodynamic performances, a feature latter used on the Concorde. An obvious visual and aerodynamic design feature was the large cantilevered delta wing, which included in-flight folding wingtips. The XB-70 was designed to use compression lift, a phenomenon also referred to as Mach wave riding, which was demonstrated with the help of wind-tunnel tests [28, 30]. It was shown to provide an increase in total lift at supersonic speeds as wingtips folded downward would capture the shock waves generated by the aircraft. Wing lift could significantly increase by up to $30 \%$ without any drag penalty [29, 30], which arguably gave the design presented by North American the edge over the Boeing concept at the end of the second and final competitive design phase* The folding wingtips also enhanced the directional stability of the vehicle even though it was still judged poor for the first vehicle variant. A wing dihedral modification by $5^{\circ}$ on the next demonstrator led to better performances. The folding wingtips also allowed for a significant reduction in fin area. Had the wings of the vehicle been fixed, the vertical fins required for stability would have been double in area to those used in the morphing capable design. Hence, this greatly reduced parasitic drag due to the vertical stabilisers and overall structural weight of the airframe. Furthermore, it also helped move the centre of lift closer to the centre of gravity at supersonic speeds, reducing the need for trim corrections. As wingtips folded, the effective wing area near the trailing edge (due to the drooping of the profile on the wingtip) was reduced, therefore decreasing the total lift aft of the centre of gravity and the needs for trim corrections. This consequently led to improved aerodynamic efficiency. For these reasons, the overall performance benefits greatly justified the use of folding wingtips

\footnotetext{
*After the final decision to select the North American concept, Boeing demanded a congressional inquiry. In the end, it appeared that the better Lift and Drag figures, enabled by the use of compression lift through the folding wingtips, which Boeing deliberately neglected by lack of faith in the concept and results, is what ultimately convinced the Air Force [28].
} 


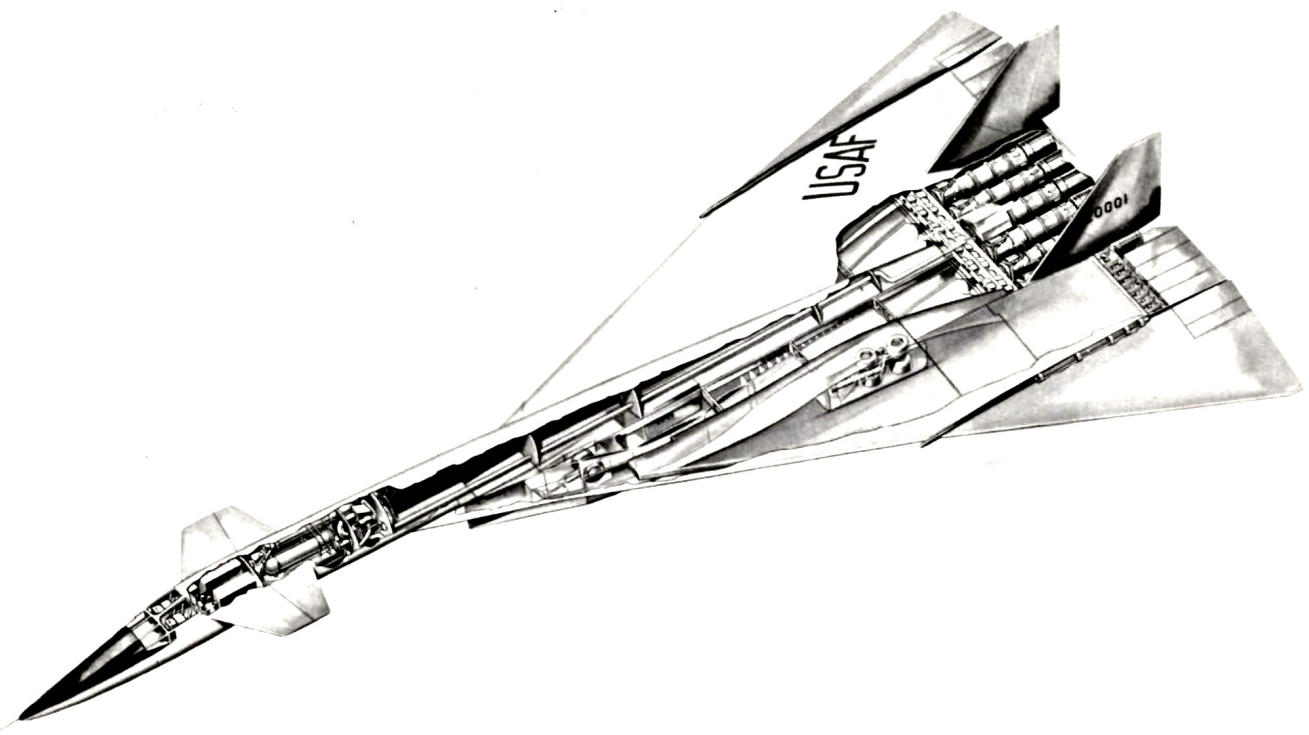

Fig. 3 XB-70 cut through engineering drawing

Note the visible hinge motors and power hinges under the thorium fairing on the right.

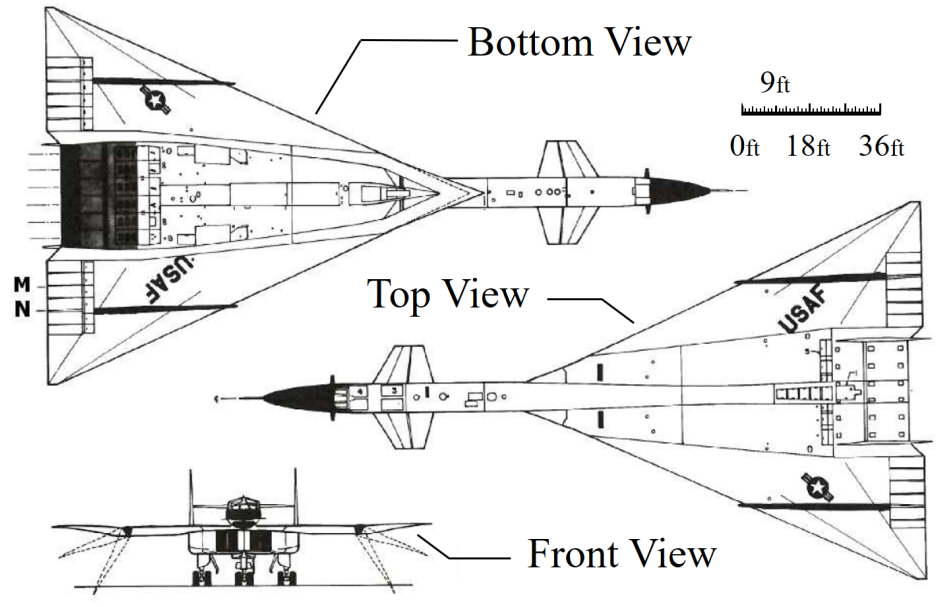

(a) XB-70 Geometric Drawings

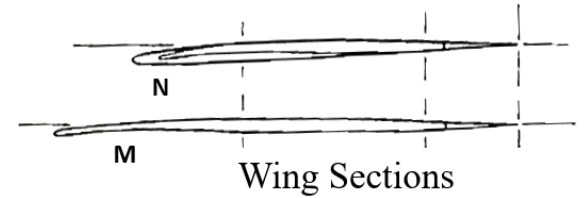

(b) XB-70 Wing Profile Sections, at both M and N truncation planes (Fig 4a)

Fig. 4 XB-70 Wing Profile and Geometric Drawings [28]

on the XB-70, despite additional mass and system complexity.

A number of significant breakthroughs were also made in many other fields, such as propulsion, engine design, materials and fuel. These advancements were necessary to ensure that the aircraft was capable of sustained supersonic high altitude flights, and cope with the thermal and structural consequences on both airframe and systems. For instance, a new honeycomb skin was developed to provide the required airframe weight reduction whilst maintaining stiffness of the overall structure. Thermal expansion and overall heating of the airframe, a phenomenon later encountered on the Concorde as well, also led to significant changes to internal systems and even livery application methods and paint composition.

But the XB-70 program never took-off to reach its original potential. Even before the tragic loss of the second XB-70 aircraft along with one of the pilots on-board [28, 29, 31], the program had been crippled by political and economic 
conflicts, and threatened by significant advancements in Inter Continental Ballistic Missiles (ICBM) and Ground-Air Missiles since the early days of development. Before the first test-flight, the program had already lost significant political momentum and funding, with the Air Force reducing the fleet to two demonstrators, with a third example, already under construction, cancelled. The project was henceforth intended for large supersonic aircraft flight research, and paved the way for the development of Super Sonic Transport (SST) such as the Concorde, but was a mere shadow of the original vehicle imagined and designed for the Strategic Air Command.

Truly captivating stories of the XB-70 project, both from an historical and political point of view, as well more specific aircraft design details can be found in excellent literature pieces [28, 29]. Though as this particular paper focuses on the folding wingtip system, the rest of the discussion will henceforth focus on the folding wingtip devices fitted on the experimental plane.

\section{Wingtip Folding at Supersonic Speeds}

As stated in the previous section, the XB-70 boasted two very large folding wingtips designed to be actuated during flight. These devices were integrated within an already truly extraordinary aircraft, and could pride upon being the largest in-flight folding lifting surfaces ever designed. Let us now take a closer look at these wingtips themselves.

\section{A. Details on the folding hinge actuator and wingtip}

One must admit that details regarding the development and characteristics of the folding wingtip actuation devices is very scarce. Most of the existing available literature focuses on the innovations which were made in the fields of aerospace materials, fuel management and engine design required by supersonic flight of such a large vehicle. Arguably, these aspects drew significantly more attention and concerns compared to the wingtip folding mechanism problem. The authors believe that, with so many other challenges and problems occurring throughout the program [28, 29], not all related to engineering, the folding wingtip device was not judged as significant to the XB-70 historical contribution.

\begin{tabular}{lcc}
\hline Folding Wingtip (Single Tip) & & \\
\hline Area & 48.39 & $\left(\mathrm{~m}^{2}\right)$ \\
Span & 6.33 & $(\mathrm{~m})$ \\
Aspect Ratio & 0.829 & \\
Taper Ratio & 0.046 & \\
Root Chord (9.67m spanwise position) & 14.61 & $(\mathrm{~m})$ \\
Tip Chord (16m spanwise position) & 0.67 & $(\mathrm{~m})$ \\
Mean Aerodynamic Chord (11.87m spanwise position) & 9.76 & $(\mathrm{~m})$ \\
Down Folding Positions from inboard wing dihedral & $0,25,65$ & $\left.{ }^{\circ}\right)$ \\
Aerofoil Thickness percent at root & 2.5 & $(\%)$ \\
\hline
\end{tabular}

Table 1 Geometric details of the XB-70 wingtip

However, enough information can be gathered to understand and reasonably estimate the capabilities of the folding hinge mechanism. Relevant geometric details regarding wingtip size and aerofoil thickness are summarised in Table 1. which gathers data obtained from various geometric drawings [28, 29] and data packs [32]. System illustrations are given in Fig 5] [28, 29]. The complete hinge mechanism is sketched in Fig. 5a, extracted from XB-70 general arrangement document. A close up picture of a Curtiss-Wright power hinge is given in Fig 6a, similar to the ones which would have been used on the Valkyrie. Accurately counting number of teeth and estimating size for retro-engineering purposes is nearly impossible. Nonetheless, the unreferenced industrial report from which the figure was extracted mentions a reduction ratio of 2440-to-1, with two stages driven by a common sun gear, giving high torque in a small diameter. Two concentric stages of reduction are used, such that the output ring gear of stage one serves as an input to the second stage as shown in Fig $6 \mathrm{~b}$. The power hinge used for the XB-70, made of two levels of two stage planetary gear systems, was similar in design and reportedly capable of an outstanding 32,000 - to -1 ratio $\left(R_{G}=32000\right)$, though it is unclear through which combination exactly such ratios were achieved as diameters and teeth numbers have not been clearly found as well as the arrangement of fixed and moving gears. This ratio is very high compared to conventional and heavier planetary gear systems. A central shaft served as an input to six power hinges distributed along the fold line 


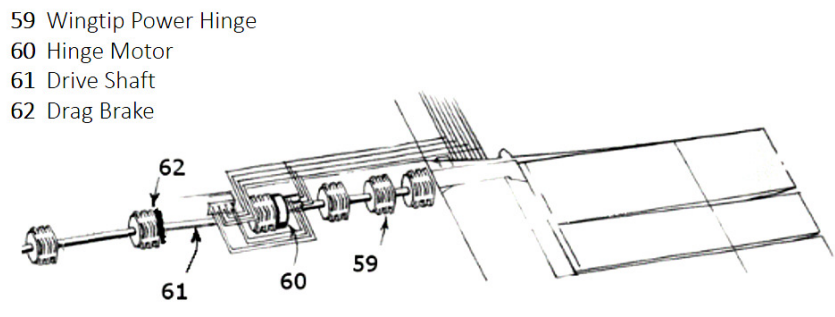

(a) Sketch of the XB-70 actuator system layout

\section{FOLD ACTUATOR-ATTACH FITTINGS}
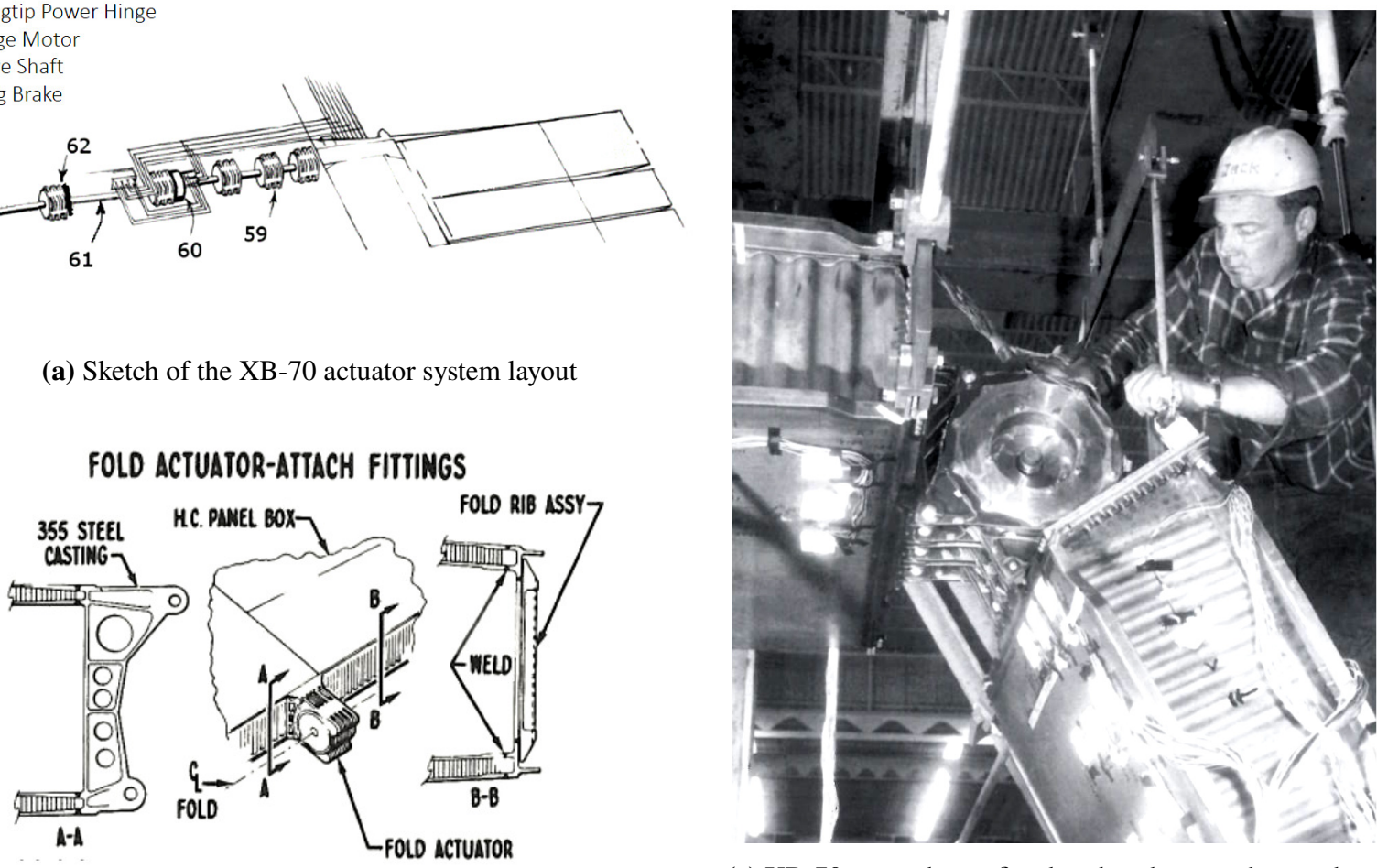

(c) XB-70 power hinge fitted within the wing box with an operator for size comparison

(b) XB-70 actuator structural implementation sketch

Fig. 5 XB-70 Folding Wingtip Hinge Motors and Actuators Details

as shown in Fig 5a Another sketch given in Fig. 5b show each power hinge was linked to the structure of the wing. A couple of Vickers hydraulic motors, situated within the fuselage, were used to pressurise the hydraulics system linked to each wingtip. For redundancy purposes, only one pump was used in the main hydraulic network, whilst the second would have been used as back-up in the event of an hydraulic pressure failure. Hence a total of 4 pumps on the aircraft dedicated solely to the wingtip mechanisms [28]. The entire wingtip actuation motor and set of power hinges were housed within a black magnesium thorium fairing which covered the entire wingtip hinge line, from wing leading edge to elevon root, as shown in the above Fig $4 \mathrm{a}$.

Obviously, this entire set of power hinges came with a significant size and mass cost to the aircraft. Exact size and mass of each power hinge remains unclear, other than advised estimates made as follows. Aerodynamic profile thickness at the fold line was estimated at best to be $36 \mathrm{~cm}$, using data from Table 1 . Evidence from pictures taken during vehicle assembly also puts the gearbox mechanism in perspective to an operator, as shown in Fig $5 \mathrm{c}$. The hinge motor appears to be roughly the diameter of an adult forearm, and fits within the dimensions of the aircraft structural wing box. Depth of the device can also be assumed to be of the same order, and therefore, the wingtip power hinge is comparable to a cube-like shape with a side of roughly $30 \mathrm{~cm}$. Made primarily of H-11 steel [30], with a room temperature density of $7.80 \mathrm{~g} / \mathrm{cm}^{3}$, weight is estimated to lie between $100 \mathrm{~kg}$ and $180 \mathrm{~kg}$ assuming a gearbox density ratio between $30 \%$ to $50 \%$. This was verified against weight estimates of other Curtiss-Wright power hinges as a function of size. But more precisely, a power hinge with similar numbers of geared elements, reduction ratio and total size was designed and sized using a dedicated in-house tool developed by the authors. This tool identified the mass of the power hinge between $140 \pm 10 \mathrm{~kg}$, with a safety margin depending on attachments thickness, shaft sizes and other parameters, narrowing previous estimates. With six devices per wingtip, the total gearbox mass per wingtip can be crudely estimated at $840 \mathrm{~kg}$, solely for the power hinges. This weight penalty then enabled the reduction of vertical fin by approximately half of its area, though little to no data is available on the structural changes to the wing required for incorporation of the hinge set. 


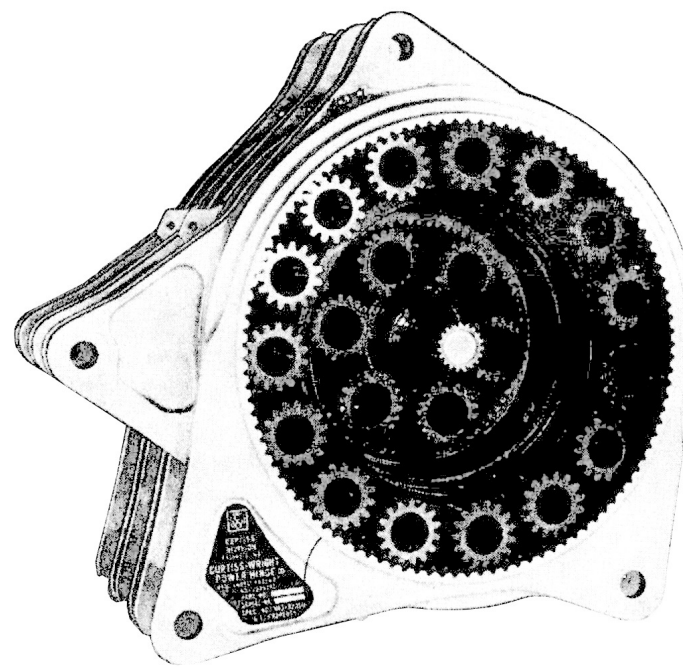

(a) A Curtiss-Wright power hinge, similar to those used on the XB-70

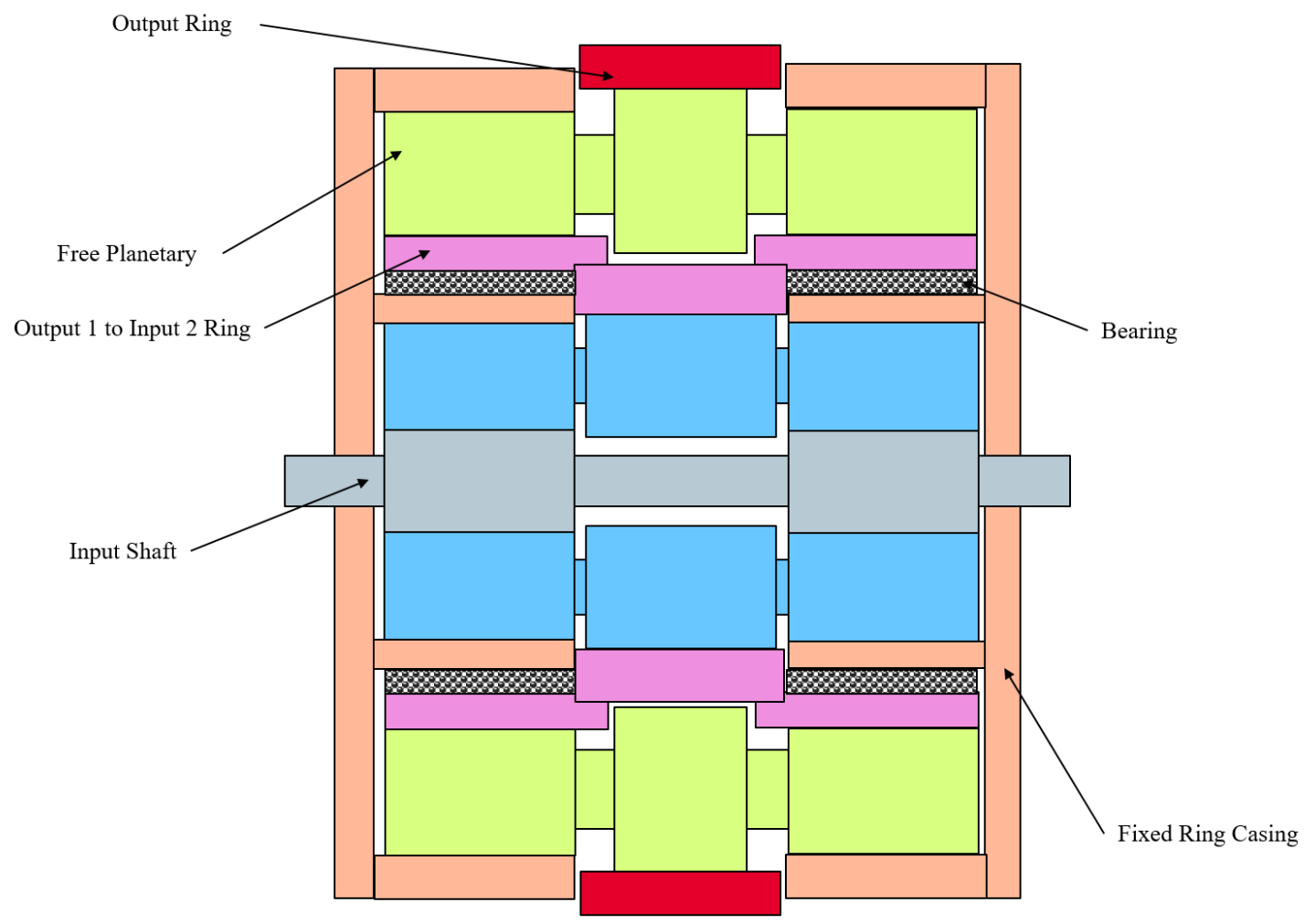

(b) Schematic cut drawing of a two level two stage planetary gear power hinge

Fig. 6 XB-70 Folding Wingtip Power Hinge Details 


\section{B. Estimating the mass savings on the fin}

To put the weight of the hinges into perspective, it is relevant to compare them to the aircraft fin and overall masses. As we know, the folding wingtips allowed for smaller fins to be used leading to a quantifiable mass saving derivation. The XB-70 had an Maximum Operating Weight (MOW) of $m_{M O W}=242500 \mathrm{~kg}$, Maximum Take Off Weight (MTOW) at $m_{M T O W}=246000 \mathrm{~kg}$, and Operating Empty Weight $(\mathrm{OEW})$ at $m_{O E W}=115030 \mathrm{~kg}$. For commercial airlines, a rough estimate of the vertical tail weight can be obtained by assuming it equal to $1 \%$ of the $m_{O E W}$. But as the XB-70 is neither a commercial airliner, nor of conventional configuration, it was decided to use the ratio of vertical fin weight over area to compute the total mass of the aircraft fins. Typical ratios, or surface densities, were computed for various commercial aircraft. Obviously, internal structures required to cope with aerodynamic stresses, materials used and to some extent profile type and thickness all contribute to differences in total fin mass between a commercial aircraft and the extensively different XB-70. But this approach was deemed sufficient to derive an estimate of comparable accuracy to that of the hinge weight. For a fin area $A_{f}$ of $21.7 \mathrm{~m}^{2}$, the surface density $\sigma_{f}$ was estimated at $23 \mathrm{~kg} . \mathrm{m}^{-2}$ in order to be similar to that of commercial aircraft with comparable fin sizes, as shown in Fig 7a. One should note from the same figure that this particular surface density of $\sigma_{f}=23 \mathrm{~kg} \cdot \mathrm{m}^{-2}$ is lower than that of commercial aircraft of comparable $m_{O E W}$, standing around $27 \mathrm{~kg} . \mathrm{m}^{-2}$. In the latter, the single fin configuration requires a larger area per fin, hence height and therefore internal structural weight to cope with the aerodynamic stresses. By having two smaller fins, the XB-70 can use a smaller surface density, effectively reducing weight for a given vertical fin area.

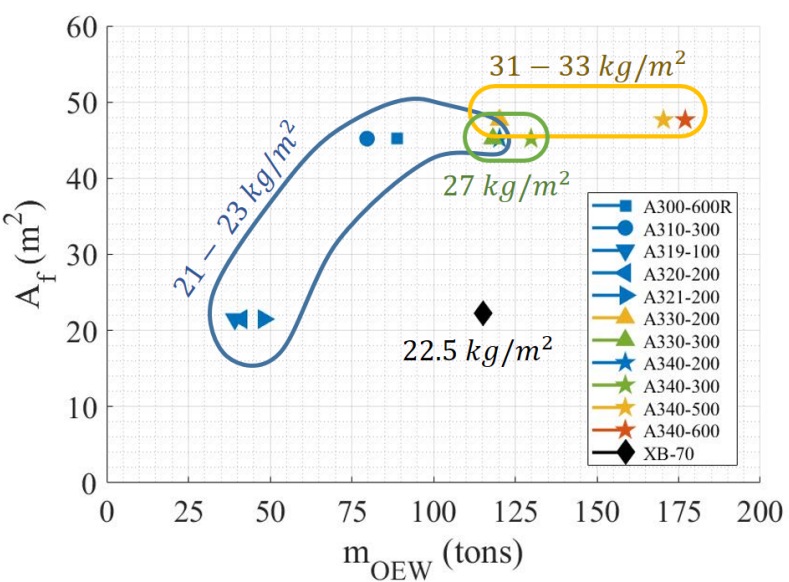

(a) Fin surface density $\sigma_{f}$ as a function of fin area $A_{f}$ and $m_{O E W}$

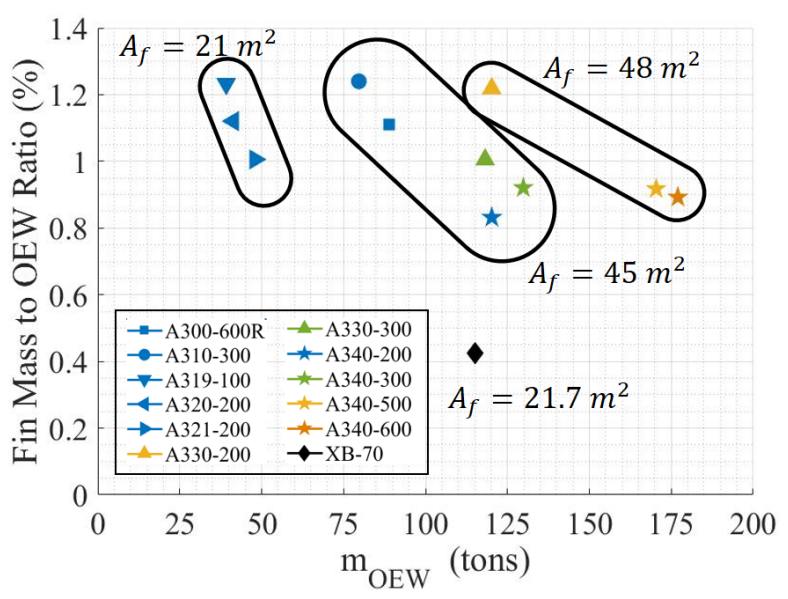

(b) Fin mass $m_{f} / m_{O E W}$ ratio as a function of $A_{f}$ and $m_{O E W}$

Fig. 7 Comparison of various civil aircraft $m_{O E W}, A_{f}$ fin area, and resulting fin mass $m_{f}$ compared against XB-70 estimates

With both fin area $A_{f}$ and surface density $\sigma_{f}$ in hand, the mass of a single fin is obtained and compared against $m_{O E W}$ as shown in Fig $7 \mathrm{~b}$ The mass of a single fin of the XB-70 was assessed at approximately $m_{f_{1}}=500 \mathrm{~kg}$, or $0.45 \%$ of $m_{O E W}$. Total mass of the fin set is therefore estimated at $m_{f_{2}}=2 \times m_{f_{1}}=1000 \mathrm{~kg}$, or $0.9 \%$ of $m_{O E W}$.

It was claimed that folding wingtips helped reduce the fin size by half by enhancing directional stability when deployed. Considering a non wingtip folding aircraft, with a single fin area of $A_{f}=43.6 \mathrm{~m}^{2}$ required for equivalent directional stability, surface density would have been set to $\sigma_{f}=27 \mathrm{~kg}_{\mathrm{g}} \mathrm{m}^{-2}$ (See Fig 7a). In turn, this would have led to one fin weighing nearly $m_{f_{1}}=1170 \mathrm{~kg}$, or slightly over $1 \%$ of $m_{O E W}$. As the XB-70 uses a dual fin configuration, that leads to fins weighing at $m_{f_{2}}=2340 \mathrm{~kg}$ or $2 \%$ of the XB-70 $m_{O E W}$.

Overall, the folding wingtip system, with the two sets of power hinges alone, weighing approximately $1680 \mathrm{~kg}$, has helped save an estimated $1340 \mathrm{~kg}$, or nearly $60 \%$ in vertical tail mass, whilst enhancing directional stability at supersonic speeds. Note that other systems, including the hydraulics, electric systems, shaft, and brakes were not accounted for in this trade-off, which makes no doubt that the mass trade here was negative. Nonetheless, it was shown that lift performance increase due to compression lift and the forward shift in the aircraft centre of lift at supersonic speeds has clearly made the system relevant, and even essential, for the XB-70 to reach required performance and control.

The reader should note that such a drastic fin area reduction was achieved for the following reasons: a) folding wingtips were deflected to very high dihedral angles (up to $65^{\circ}$ ) and effectively served as additional fins and b) the delta wing configuration placed the folding tips near the tail of the aircraft, or nearly aligned with the vertical fins of the 
vehicle. This in turn, allowed for much more authority around the vertical axis given the forward position of the centre of lift and centre of gravity. In comparison, if such a device were to be used in a conventional aircraft configuration, the wingtip position along the longitudinal axis would not be as far aft, greatly reducing the authority of the now additional fins. Nonetheless, if weight savings could be achieved by reducing vertical tail size, even to less drastic extents, it would still greatly help in the case for in-flight folding wingtip device implementation.

\section{Assessing the power hinge capabilities}

Following the estimation of actuator size and mass, the torque or loading capability of the device is now of interest. Of course, the necessity to use six power hinges was inherently linked to the required actuation moment to move the massive wingtips consistently throughout the flight envelope and cope with the inherent twist and bend stresses. Even though none of the demonstrator vehicles ever flew with fuel in the wingtip tanks, the mechanism was sized accordingly, and therefore over sized. It is unclear whether the actuators were designed to deal with a single component failure, as this was an experimental military aircraft. Hence, it shall be assumed that each of the power hinges were designed to cope with a sixth of the maximum allowable hinge moment (no safety margin). This should give us a conservative estimate of the maximum allowable hinge moment or torque per actuator.

To do so, the nominal folding strategy of the XB-70 wingtips was investigated and is illustrated in Fig 8 From these graphs, it is clear that wingtips were to be held planar until high transonic speeds. At Mach 0.9, the wingtips would have been folded to a $25^{\circ}$ downward angle. This dihedral fold would then be further increased upon reaching Mach 1.4 to a $65^{\circ}$ deflection, and maintained throughout the higher end of the velocity spectrum.

Valuable in-flight data and measurements obtained using strain gauges to measure the hinge moments at multiple flight conditions were extracted from a NASA report [32]. Approximations of the folding wingtip hinge moment coefficients were then made in the report and are redrawn in Fig $9 \mathrm{~b}$. These coefficients correspond to an entire set or wingtip device (a combination of all six power hinges and motor). The coefficients can then be scaled back to the equivalent hinge moment acting on the device using Eqn 1, which is similar to the equation conventionally used for ailerons, elevators or rudders, also found in the original NASA document [32]. The relationship between the hinge moment coefficient and corresponding moment is given by:

$$
\begin{aligned}
C_{h_{w t}} & =\frac{H_{w t}}{\bar{q} \times S_{e} \times l_{w t}} \\
\equiv \quad H_{w t} & =C_{h_{w t}} \times\left(\bar{q} \times S_{e} \times l_{w t}\right)
\end{aligned}
$$

where $C_{h_{w t}}$ is the hinge moment coefficient acting around the fold line (bending), $\bar{q}$ is dynamic pressure, $S_{e}$ is the wingtip surface area and $l_{w t}$ is the wingtip length. The last two are geometric variables given in Table 1$]$ whilst $C_{h_{w t}}$ and dynamic pressure $\bar{q}$ are both functions of the flight conditions at which the measurements were made, the details of which are provided in Table 2 [32]. Dynamic pressures used in this study were derived using the compressibility corrections and atmospheric temperature models adequate for high altitude supersonic flight conditions, highlighted in Appendix A Note that the dynamic pressures computed are comparable but not strictly identical to those given in the NASA report [32].

With the dynamic pressure $\bar{q}$ and hinge moment coefficients $C_{h_{w t}}$ in hand, it was possible to derive the hinge moment $H_{w t}$ using Eqn 1. Both $C_{h_{w t}}$ and $H_{w t}$ are illustrated in Fig 9a and Fig $9 \mathrm{~b}$ as a function of flight conditions at which they were made. The general trend shows an increase in bending moment with angle of attack $\alpha$, as expected: the lift produced on the lifting surface increases as the aircraft pitches up relative to the flow. Counter intuitively, or what may seem like it, the maximum hinge moments are not obtained at the higher Mach numbers because: a) air density reduces, and therefore counter acts the effect of increasing airspeed, b) as the wingtips are folded downwards, the profile shape induces a reduction in lift [28, 29], and c) the trimmed angle of attack reduces with airspeed and altitude, further reducing the lift acting on the wingtip.

In fact, the highest bending moments $M_{x}$, reaching up to $700 \mathrm{kN} . \mathrm{m}$ were obtained in the lower supersonic regions with a $25^{\circ}$ deflection. At higher speeds and altitudes, the hinge moment acting on the further deflected wingtips appears to be lower despite higher speeds. In the subsonic region, the hinge moment lays within $450 \mathrm{kN} . \mathrm{m}$ and $600 \mathrm{kN} . \mathrm{m}$, with very little difference between the baseline and $25^{\circ}$ deflection cases. As a single motor was used, the gear ratio $R_{G}$ of 32,000-to-1 suggests that, in the case of an idealised system (no friction), a maximum torque $T_{\text {shaf }}^{\text {max }}=22 N . m$ $\left(M_{x}^{\max } / R_{G}\right)$ was required to drive the shaft feeding through all power hinges. In reality, the required torque would have been significantly larger, due to friction and mechanical efficiency. But note that comparable torques can be easily achieved using electric or hydraulic rotary motors with diameters well below $30 \mathrm{~cm}$. 


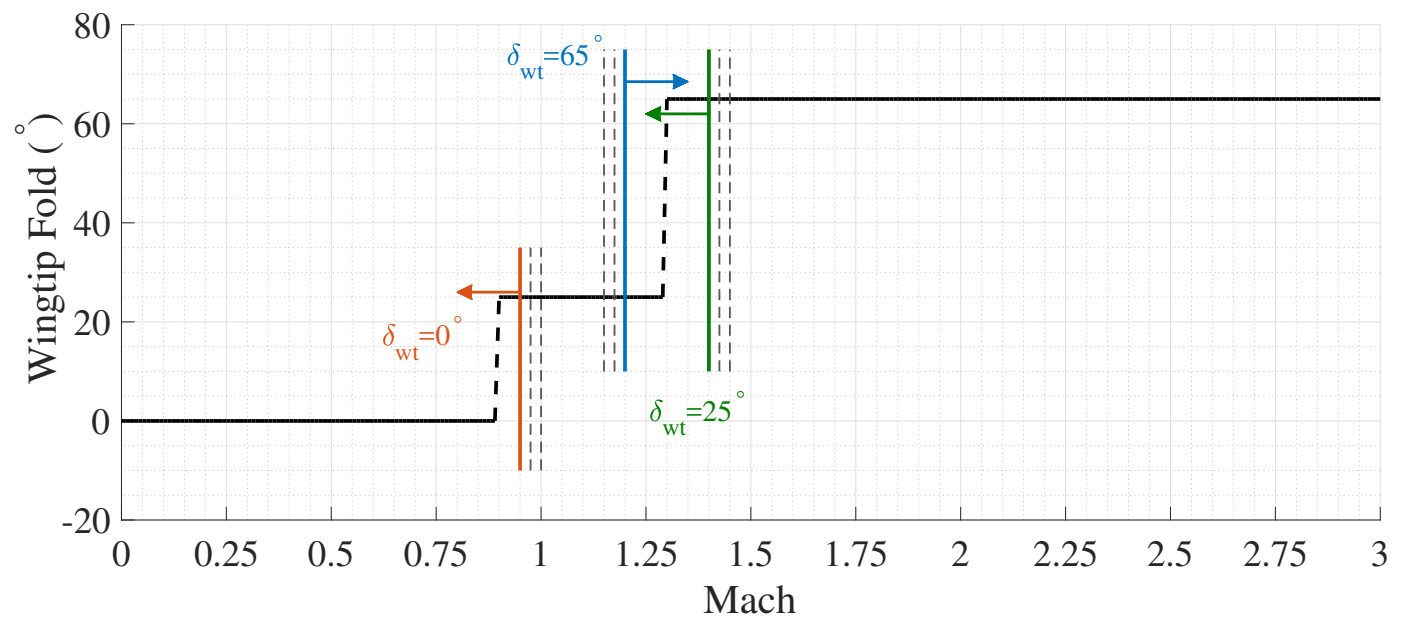

(a) XB-70 nominal folding strategy

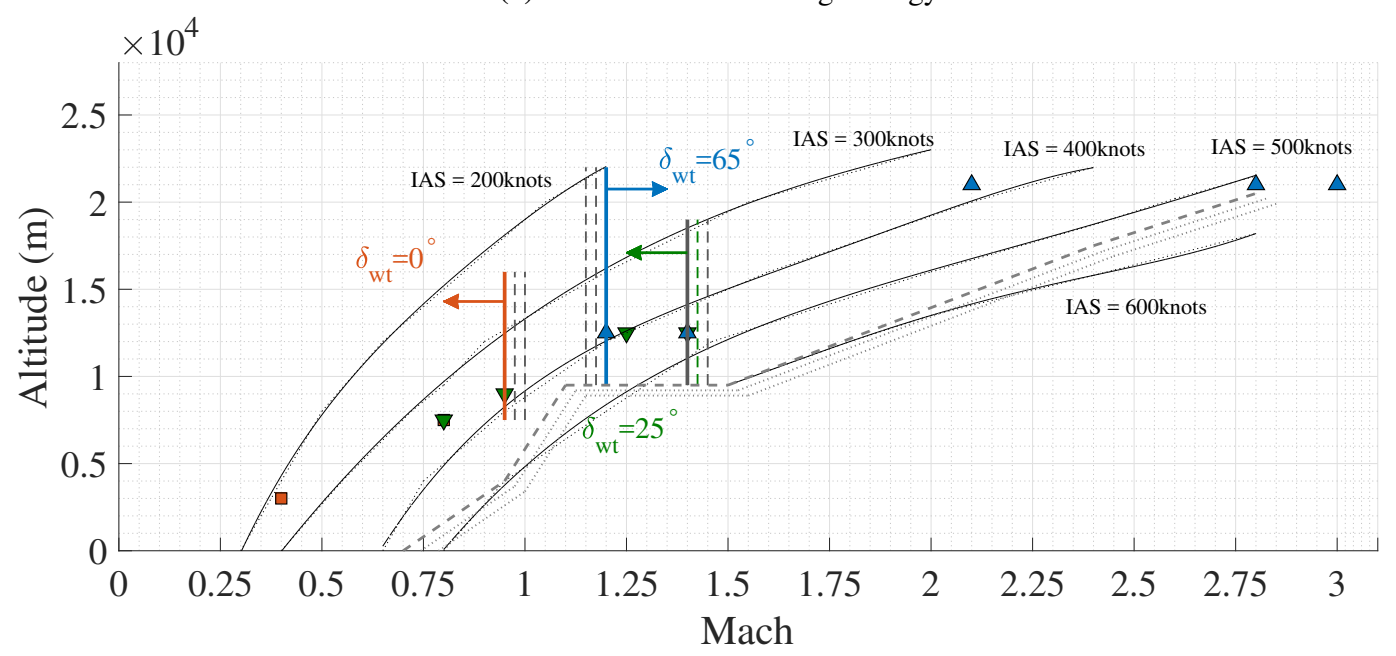

(b) XB-70 typical flight envelope, with folding limitations and flight conditions listed in Table 2

Fig. 8 XB-70 nominal folding wingtip strategy for the aircraft entire flight envelope

Derived from both trimmed steady flight and coordinated turns [32], these results are reliable indicators of the power hinge capacity to withstand aerodynamic loads and fold the wingtips in flight. These figures clearly show that the wingtip folding devices were capable of coping with high bending moments. Note that none of the tests included loaded wingtip fuel tanks, for which the system was designed originally, and are therefore conservative.

Another point of interest for this study is wingtip shaft rotational speed $R P M_{\text {shaft }}$ during wingtip rotation. With the reduction ratio $R_{G}$ of the power hinges, and data extracted from non accelerated footage of in-flight folding of the wingtips, it is possible to get an estimate of the shaft rotational speed in revolutions per minute. A video sample was used to measure both time to fold from ideal $0^{\circ}$ to $25^{\circ}, t_{0^{\circ}-25^{\circ}}$ and change in fold angle during that time $\Delta \Gamma$. $R P M_{\text {shaft }}$ is calculated using Eqn $2 . t_{0^{\circ}-25^{\circ}}$ was estimated at $17 \pm 0.5 \mathrm{~s}$ and $\Delta \Gamma$ was assumed ideal at $25^{\circ}$, but a minimum $\Delta \Gamma=20^{\circ}$ was also considered. These parameters led to an approximation of $R P M_{\text {shaft }}=8000 \mathrm{rpm}$ with a maximum of $8100 \mathrm{rpm}$ and as low as $6100 \mathrm{rpm}$ in the worst measurement case $\left(t_{0^{\circ}-25^{\circ}}=17.5, \Delta \Gamma=20^{\circ}\right)$. This value sits well within the range of realistic motor capabilities which could be fitted within the wing.

$$
R P M_{\text {shaft }}=R_{G} \times \frac{\Delta \Gamma \times 60}{t_{0^{\circ}-25^{\circ} \times 360}}
$$

Overall, the size, mass and actuation power of the folding mechanism fitted on the XB-70 have been presented in 


\begin{tabular}{ccccc}
\hline \hline \multicolumn{5}{c}{ Flight Conditions for Hinge Moment Coefficient } \\
\hline FC & Mach & Altitude $(\mathrm{m})$ & Fold Angle $\delta_{w t}\left(^{\circ}\right)$ & $\bar{q}\left(N . m^{-2}\right)$ \\
1.1 & 0.4 & 3000 & 0 & 7850 \\
1.2 & 0.8 & 7620 & 0 & 16841 \\
2.1 & 0.8 & 7620 & 25 & 16841 \\
2.2 & 0.95 & 9144 & 25 & 19005 \\
2.3 & 1.2 & 12190 & 25 & 20379 \\
2.4 & 1.4 & 12190 & 25 & 27738 \\
3.1 & 1.25 & 12190 & 65 & 22113 \\
3.2 & 1.4 & 12190 & 65 & 27738 \\
3.3 & 2.1 & 15000 & 65 & 45991 \\
3.4 & 2.8 & 21340 & 65 & 26990 \\
3.5 & 3 & 21340 & 65 & 30984 \\
\hline \hline
\end{tabular}

Table 2 List and details of the flight conditions used for hinge moment measurements on the XB-70 folding wingtip device

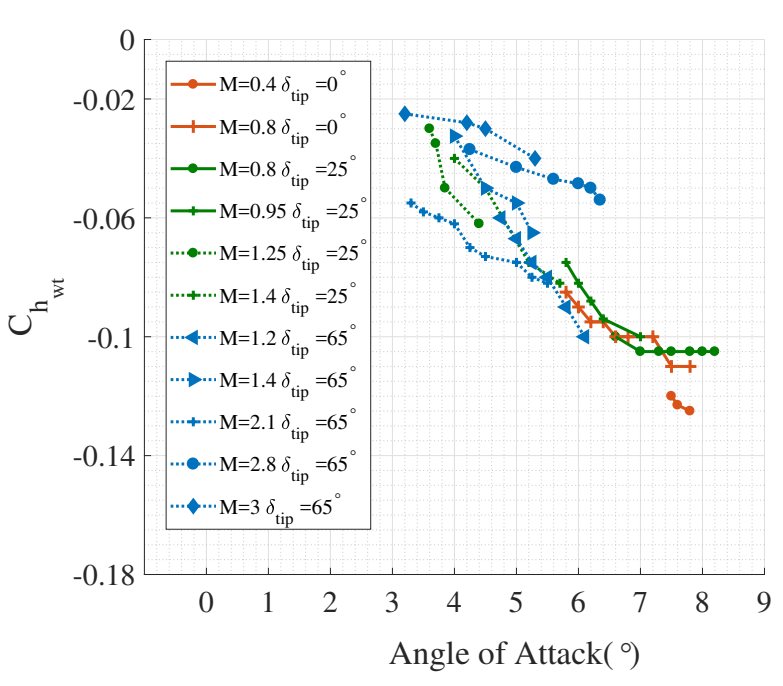

(a) Hinge moment coefficient $C_{h_{w t}}$

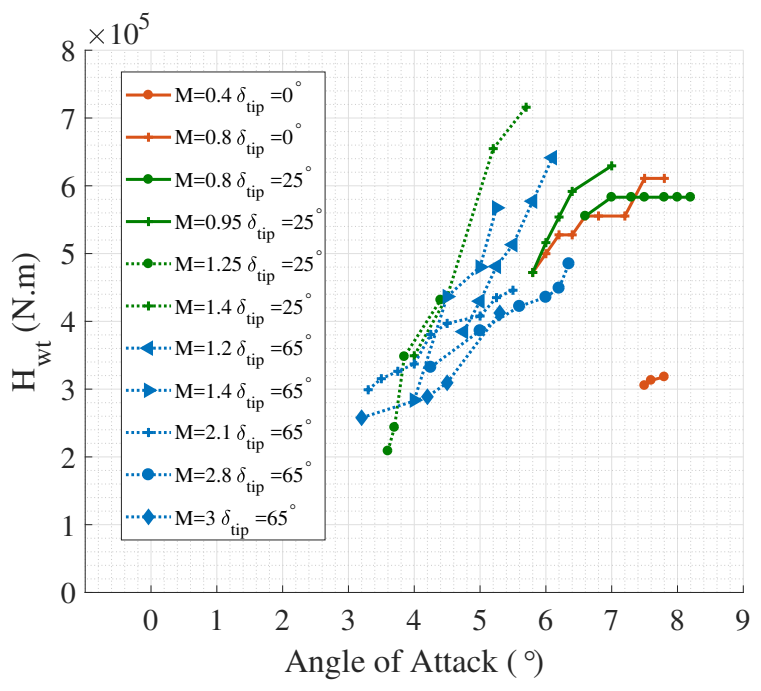

(b) Hinge moment $H_{w t}$ dimensionalised using Eqn 1

Fig. 9 XB-70 folding wingtip hinge moment coefficients and dimensionalised results from flight test measurements

this section. It is now clear that powerful in-flight wingtip actuators have been used in the past for military applications, and could potentially serve as inspiration to future civil concepts. The following step is naturally to compare these results against a number of wing box and assess if such a device could be used in the frame of folding wingtips on a large civil aircraft.

\section{Inspiration for a large civil aircraft design}

In this section, we will tackle the idea of using a similar system to that of the XB-70 in a number of use-case aircraft wing box. In fact a span extended single aisle aircraft wing concept was used as a baseline and scaled to various sizes. The spanwise position of the wingtip hinge was kept constant and consistent with ground operational limitations. Hence the challenge is to fit a sufficient number of power hinges within a thinner aerofoil profile and shorter chord length than those of the XB-70. Aerodynamic loads should also differ substantially, as flight conditions are drastically different. 


\section{A. Design space calculations}

With different wings come different aerodynamic profile thickness, chord, and aerodynamic loading in cruise. The aircraft wing aerodynamic and structural properties were implemented within a geometrical initialisation environment derived from $C A^{2} L M$, a aeroservoelastic framework developed at Cranfield University [33, 34], with specific initialisation and data extraction codes dedicated to the folding wingtip sizing process. An illustration of the wing once implemented within the framework is given in Fig. 10. The baseline wing was modified in chord $\bar{c}$, thickness $t$ and span $s$ using a global scaling factor so that root chord $\bar{c}_{r}$, tip chord $\bar{c}_{t}$, span and profile thickness to chord ratio at the hinge line $t / \bar{c}_{h}$ vary. This multi-dimensional scaling of the wing, be it non realistic, should still give a sufficiently precise idea of available dimensions as a function of wing size. The full list and details of the wings investigated herein is given in Table 3 with the original baseline wing in bold. The hinge line central point (intersection with the centre chord position) was fixed at $17 m$ to cope with ground limitations for all wings, hence a change in wingtip length $l_{w t}$ is introduced.

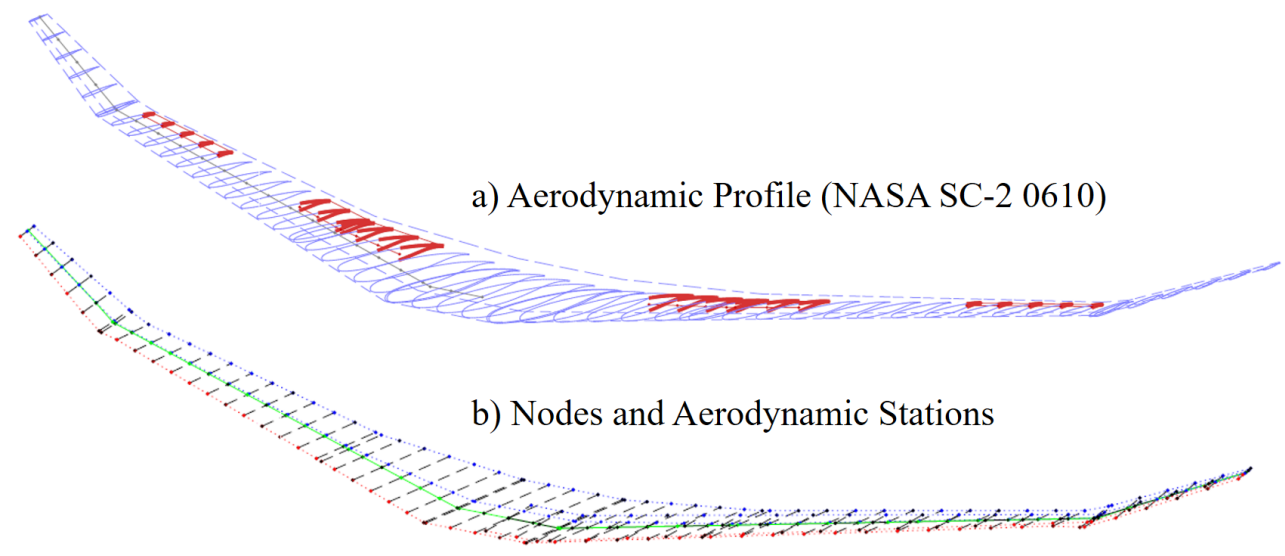

Fig. $1022.5 \mathrm{~m}$ semispan wing layout after geometric implementation within the framework, with a folded wingtip at $17 \mathrm{~m}$, folded upward by $15^{\circ}$.

Hinge flare is a key feature of the folding device envisioned for loads alleviation in the scope of this academic research project. It leads to local angle of attack reduction as a function of fold angle, as demonstrated in previous work [24, 25]. A single flare angle $\Lambda^{\text {hinge }}=20^{\circ}$ is used herein. To account for this flare angle, a simple geometric correction was applied. This led to corrected wing leading and trailing edge hinge line positions and a new flared chord length $c_{\bar{h}} r$ was obtained. The impact of the hinge line flare angle on chord length is clearly shown in Fig. 11. Interestingly, the combination of both leading and trailing edge sweep angles leads to a rotated chord $c_{\bar{h}} r$ at the selected flare angle of $20^{\circ}$ as one of the smallest possible values for the given geometry. In other words, by flaring the hinge around the centre chord (and even the leading edge), the available chord length before an aerodynamic fairing becomes necessary is effectively reduced. In more ways than not, flaring the hinge line leads to a more restrictive design space as out-of-line fairings and reduced chord become problematic, but is a necessary feature to achieve efficient off-load. Profile sizing results are given in Table 5, with both line of flight and rotated chord lengths $\overline{c_{h}}$ and $\overline{c_{h}}$ and maximum hinge thickness at the hinge line $t_{h}$.

From these spatial sizing results, it is possible to have an appreciation of the size of the available profile compared to that of the XB-70. A visual comparison is made in Fig. 12 where both XB-70 and baseline civil wing are shown. It is clear that, where six power hinges could easily be fitted within the XB-70 wing, it is widely different in the case of the civil aircraft wing, regardless of the variant. The profile is both too thin to fit a power hinge without using an aerodynamic fairing and too short to fit six along the hinge line. But it should not need to. With smaller wingtips and different flight conditions, hinge bending moments may not lead to such massive wingtip actuation devices, as we will see in the following section.

\section{B. Loads scalability to the civil aircraft wing}

Internal investigations were made within Airbus to identify the aerodynamic forces and moments acting on the hinge line at cruise, for different wing variants. These results are provided in Table 5 , with the baseline wing characteristics and loading in bold. Focusing solely on the hinge bending loads, it was found that a maximum of $200 \mathrm{kN} . \mathrm{m}$ would 


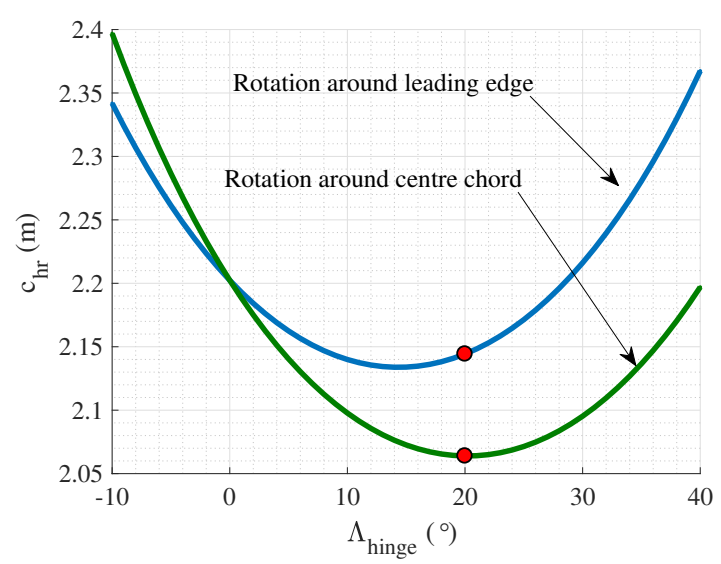

(a) Rotated chord length size changes with hinge flare angle and rotation centre

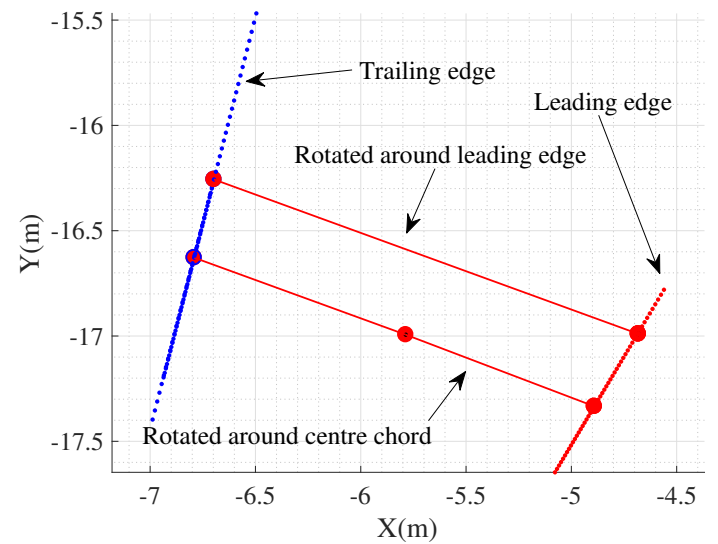

(b) Hinge line position over a simplified planform view with leading and trailing edge paths

Fig. 11 Rotated chord length with flare angle investigation for the $22.5 \mathrm{~m}$ semispan wing.

\begin{tabular}{ccccc}
\hline \hline \multicolumn{6}{c}{ Wing Characteristics } \\
\hline \hline$N^{\circ}$ & $s(\mathrm{~m})$ & $\bar{c}_{r}(m)$ & $\bar{c}_{t}(\mathrm{~m})$ & $t / \bar{c}_{h}(\%)$ \\
\hline 1 & 21 & 5.813 & 0.703 & 10.9 \\
$\mathbf{2}$ & $\mathbf{2 2 . 5}$ & $\mathbf{6 . 2 0 0}$ & $\mathbf{0 . 7 5}$ & $\mathbf{1 1 . 0}$ \\
3 & 24 & 6.643 & 0.804 & 11.2 \\
4 & 25 & 6.920 & 0.837 & 11.3 \\
5 & 26 & 7.200 & 0.871 & 11.4 \\
\hline \hline
\end{tabular}

Table 3 Simple geometric details of the various wings investigated

\begin{tabular}{ccccc}
\hline \hline \multicolumn{6}{l}{ Wing Characteristics at Hinge } & & \\
\hline \hline$N^{\circ}$ & $\bar{c}_{h}(\mathrm{~m})$ & $\bar{c}_{h r}(\mathrm{~m})$ & $l_{w t}(\mathrm{~m})$ & $t_{h}(\mathrm{~m})$ \\
\hline 1 & 1.780 & 1.712 & 4 & 0.194 \\
$\mathbf{2}$ & $\mathbf{1 . 8 9 9}$ & $\mathbf{1 . 8 2 9}$ & $\mathbf{5 . 5}$ & $\mathbf{0 . 2 0 9}$ \\
3 & 2.035 & 1.967 & 7 & 0.230 \\
4 & 2.120 & 2.054 & 8 & 0.242 \\
5 & 2.205 & 2.144 & 9 & 0.253 \\
\hline \hline
\end{tabular}

Table 4 Resulting wing characteristics at hinge position for a flare angle of $20^{\circ}$.

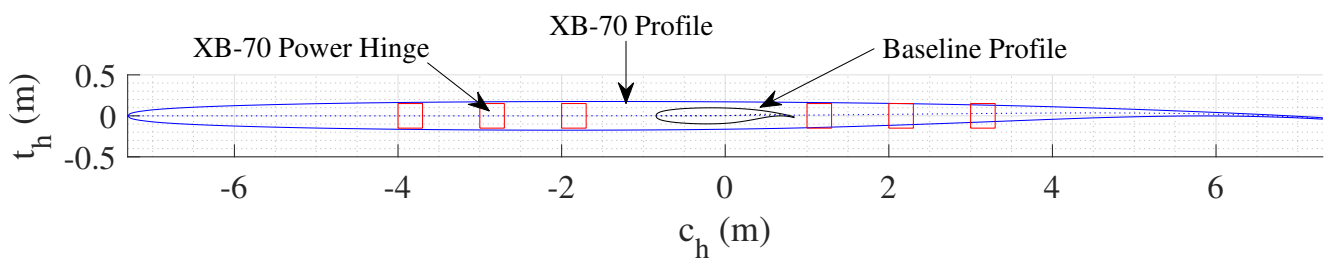

Fig. 12 Profile size comparison between the XB-70 wing and the wing of interest (NASA SC-2 0610 Profile used for illustrative purpose)

be reached in cruise conditions for the larger wing variant, whilst the baseline wing would only have to fight against $80 k N . m$. This is well below the XB-70 values derived in the previous sections and points to a possible reduction in the required number and ratio of the power hinges, effectively reducing the size of the entire actuation system. In fact, if similar hinges in reduction ratio were to be implemented, the system could do with just a pair of actuators on each wing. In their current state, an aerodynamic fairing would obviously be required, a daunting engineering task as the hinge line is not aligned with the stream flow in the present set-up. If the diameter of the reduction stages were to exceed profile thickness, motor and reduction stages would have to be placed line of flight before transmitting the output through another angled shaft aligned with the hinge line for example. It is also possible to use multiple, yet smaller power hinges and motors to help with redundancy and sizing of the system. It could also greatly improve the final solution and cut out the needs of an aerodynamic fairing.

Overall, it was found that despite being significantly larger than the available space, the use of conventional hinged 


\begin{tabular}{cccc}
\hline \multicolumn{5}{l}{ Wing Characteristics at Hinge } \\
\hline$N^{\circ}$ & $s(\mathrm{~m})$ & $l_{w t}(\mathrm{~m})$ & $M_{x}(k N . m)$ \\
\hline $\mathbf{2}$ & $\mathbf{2 2 . 5}$ & $\mathbf{5 . 5}$ & $\mathbf{8 0}$ \\
4 & 25 & 8 & 170 \\
5 & 26 & 9 & 200 \\
\hline
\end{tabular}

Table 5 Resulting wing characteristics at hinge position for a flare angle of $20^{\circ}$.

actuation for the folding wingtip concept is not far-fetched in terms of dimensional sizing requirements. As both wingtip systems would be used differently and deal with different torque and loads requirement, it was possible to nuance the gap in size. The final device fitted on the civil aircraft wing would clearly not need as many and massive power hinges.

\section{Conclusions and Further Work}

\section{A. Conclusion}

In this paper, the authors have presented a quick overview of the history behind the development of the XB-70 Valkyrie, with an emphasis on the needs and benefits for the folding wingtips. It is clear from historical sources that the folding wingtips have led to a reduction in fin area, enhanced directional stability at supersonic speeds, and increased lift performances by benefiting from more compression lift. The specific details of the hinge devices and actuation were then derived, as very little data is currently available. Using flight test reports and geometrical data sheets, the number, size, weight and actuation capabilities of the power hinges and motors were estimated. Each power hinge was found to weigh approximately $140 \mathrm{~kg}$, and are roughly equivalent to $30 \mathrm{~cm}$ sided cubes in size. The 32,000-to- 1 ratio of the power hinges allowed for a shaft rotating at approximately $8000 \mathrm{r} \mathrm{pm}$ in order to output wingtip rotational speeds of $0.25 \mathrm{rpm}$. The extremely high bending moments, estimated as up to $700 \mathrm{kN} . \mathrm{m}$ during flight test, could therefore become easily manageable by a relatively small motor. An estimate of the weight penalty due to the additional power hinge mass was also compared to the fin weight savings using conventional aircraft fin surface densities. It was found that overall, the weight penalty and savings were equivalent, allowing for overall better performances and above mentioned benefits of the folding wingtips. Lastly, the scalability of the folding device was assessed against a conventional civil aircraft. A set of wings were used to assess available design space at the hinge line situated at $17 \mathrm{~m}$ from the central line, to respect airport size limitations. It was found that despite being too thin and short to house the XB-70 actuation system, a similar approach could be scaled down, as different loads, flight conditions and wingtips are considered in this use case. If 3 power hinges or gear reduction systems were used in parallel instead of six, the effective loads per actuator would still half those encountered in the XB-70 for the larger wing variant, and less than a fifth for the baseline wing, thus allowing for significant downsizing possibilities of the system. Whilst not dismissing the idea of having lighter and more power dense solutions in SMA alternatives, this investigation shows that an electric motor and gearbox or power hinge combination as found on the XB-70 could be considered for short term applications due to their respective technology readiness level.

\section{B. Additional discussion points}

Nonetheless, the authors do believe that a few additional statements should be made to fully cover the research that was carried out.

Firstly, it must be stressed out that maintenance requirements and life cycle expectations of the power hinges may be inadequate for viable commercial applications. This obviously was not an issue for the experimental military project, having been reduced to barely more than 200 cumulated flight hours throughout the program, but could be a potential show-stopper when applied to civil commercial aircraft. As military certifications strongly diverge from those used in the civil sector, what seemed acceptable for the XB-70 aircraft in terms of life cycle and maintenance implications may become unacceptable for our use case. Had the program gone through the experimental stages and into active service, a precious insight on the long term use and maintenance of such devices would have been gained.

Furthermore, a significant fin mass and area reduction was achieved by using folding wingtips on the XB-70. Such drastic changes should not be expected for the reasons already highlighted in Section III] Different configurations of commercial aircraft would benefit differently as moving the wingtips further aft (delta wing Concorde-like configurations) 
or forward (low swept HARW) would respectively increase and decrease the directional stability changes. In the case of the conventional tubular swept wing, wingtips being placed only slightly aft of the centre of lift and centre of gravity only yields a small increase in restoring yawing moment or stability as the longitudinal moment arm is so small. Furthermore, the wingtips on the XB-70 were, as previously outlined, the biggest movable surfaces ever designed and therefore, led to significant changes in vertical lift surface area when deflected.

\section{Furtherwork}

In the scope of the Airbus led in-flight folding wingtip research project, no immediate further investigations are considered regarding the XB-70 hinged wingtips. But significant challenges remain, as most of the results presented herein, extracted from enlightened assumptions and mathematical predictions, could greatly benefit from validation against real aircraft data. Interesting results could be highlighted by further investigating high gear reduction system similar to the Curtiss-Wright design for instance.

To complete the sizing analysis for large civil aircraft applications, additional system sizing should also be carried out, including the sizing of hydraulic and elecric actuators as a function of required torque for instance. Initial sizing methods for early design and protoype development stages were investigated by the authors concurrently to this work [35]. Non conventional actuation such as Shape Memory Alloy (thermal or magnetic) and their scaling potential should also be investigated, as they could lead to lighter and more power dense solutions, as recently shown in the SAW project led by NASA and Boeing researchers[22, 23].

\section{Acknowledgments}

This work is supported and developed by Cranfield University and in collaboration with Airbus Group and Innovate UK, as part of the aircraft wing integration project. The author would also like to acknowledge Bob Thompson and James Fish for their help in finding relevant sources of information regarding the XB-70 aircraft.

\section{References}

[1] Bradley, M., and Droney, C., “Subsonic Ultra Green Aircraft Research: Phase II,” Tech. rep., 2012. Doi:2060/20150017039.

[2] Hayes, D., Lone, M., Whidborne, J., and Coetzee, E., "Evaluating the Rationale for Folding Wing Tips Comparing the Exergy and Breguet Approaches," 55th AIAA Aerospace Sciences Meeting, 2017. Doi:10.2514/6.2017-0464.

[3] Weisshaar, T., "Morphing aircraft technology-new shapes for aircraft design," Multifunctional Structures / Integration of Sensors and Antennas, 2006, p. 20. Doi:10.14339/RTO-MP-AVT-141.

[4] McGowan, A.-M., Vicroy, D., Busan, R., and Hahn, A., "Perspectives on Highly Adaptive or Morphing Aircraft," RTO Applied Vehicle Technology Panel (AVT) Symposium, 2009, pp. 1-14.

[5] Min, Z., Kien, V. K., and Richard, L. J., “Aircraft morphing wing concepts with radical geometry change,” The IES Journal Part A: Civil \& Structural Engineering, Vol. 3, No. 3, 2010, pp. 188-195. Doi:10.1080/19373261003607972.

[6] Barbarino, S., Bilgen, O., Ajaj, R. M., Friswell, M. I., and Inman, D. J., "A Review of Morphing Aircraft," Journal of Intelligent Material Systems and Structures, Vol. 22, No. 9, 2011, pp. 823-877. Doi:10.1177/1045389X11414084.

[7] Campanile, L., "Initial Thoughts on Weight Penalty Effects in Shape-adaptable Systems," Journal of Intelligent Material Systems and Structures, Vol. 16, No. 1, 2005, pp. 47-56. Doi:10.1177/1045389X05046692.

[8] Previtali, F., "Morphing Wing Based on Compliant Elements,” Ph.D. thesis, 2015. Doi:10.3929/ethz-a-010546627.

[9] Ajaj, R., Flores, E., and Friswell, M., "Variable Wing Span Using the Compliant Spar Concept," 54th AIAA/ASME/ASCE/AHS/, 2013. Doi:10.2514/6.2013-1451.

[10] Ajaj, R., Beaverstock, C., and Friswell, M., "Morphing aircraft: The need for a new design philosophy," Aerospace Science and Technology, Vol. 49, No. January, 2015, pp. 154-166. Doi:10.1016/j.ast.2015.11.039.

[11] Hartl, D. J., and Lagoudas, D. C., "Aerospace applications of shape memory alloys," Proceedings of the Institution of Mechanical Engineers, Part G: Journal of Aerospace Engineering, Vol. 221, No. 4, 2007, pp. 535-552. Doi:10.1243/09544100JAERO211.

[12] Thill, C., Etches, J., Bond, I., Potter, K., and Weaver, P., “Morphing skins,”, 2008. Doi:10.1017/S0001924000002062. 
[13] Seigler, T., Bae, J.-S., and Inman, D., "Flight control of a variable span cruise missile," ASME $2004,2004$. Doi:10.1115/IMECE2004-61961.

[14] Seigler, T., "Dynamics and Control of Morphing Aircraft," Phd, Virginia Polytechnic Institute and State University, 2005. Doi:10.1.1.100.951.

[15] Seigler, T., Neal, D., Bae, J.-S., and Inman, D., “Modeling and Flight Control of Large-Scale Morphing Aircraft,” Journal of Aircraft, Vol. 44, No. 4, 2007, pp. 1077-1087. Doi:10.2514/1.21439.

[16] Bowman, J., Sanders, B., Cannon, B., Kudva, J., Joshi, S., and Weisshaar, T., "Development of Next Generation Morphing Aircraft Structures," 48th AIAAASMEASCEAHSASC Structures Structural Dynamics and Materials Conference, , No. April, 2007, pp. 1-10. Doi:10.2514/6.2007-1730.

[17] Bye, D., and McClure, P., "Design of a Morphing Vehicle," 48th AIAA/ASME/ASCE/AHS/ASC Structures, Structural Dynamics, and Materials Conference, American Institute of Aeronautics and Astronautics, Reston, Virigina, 2007. Doi:10.2514/6.20071728.

[18] Kota, S., Osborn, R., Ervin, G., Maric, D., Flick, P., and Paul, D., "Mission Adaptive Compliant Wing - Design , Fabrication and Flight Test," Tech. rep., 2006.

[19] Bourdin, P., Gatto, A., and Friswell, M., “Aircraft Control via Variable Cant-Angle Winglets," Journal of Aircraft, Vol. 45, No. 2, 2008, pp. 414-423. Doi:10.2514/1.27720.

[20] Ursache, N., Melin, T., Isikveren, A., and Friswell, M., “Technology Integration for Active Poly-Morphing Winglets Development," Smart Materials, Adaptive Structures and Intelligent Systems, Volume 1, , No. April 2015, 2008 , pp. 775-782. Doi:10.1115/SMASIS2008-496.

[21] Peel, L., Mejia, J., Narvaez, B., Thompson, K., and Lingala, M., "Development of a Simple Morphing Wing Using Elastomeric Composites as Skins and Actuators," Journal of Mechanical Design, Vol. 131, No. 9, 2009. Doi:10.1115/1.3159043.

[22] Kamlet, M., and Gibbs, Y., “NASA Tests New Alloy to Fold Wings in Flight,”, 2018.

[23] Warwick, G., “NASA Says Wing-Folding In Flight Saves Fuel,”, 2018.

[24] Castrichini, A., Hodigere Siddaramaiah, V., Calderon, D. E., Cooper, J. E., Wilson, T., and Lemmens, Y., "Nonlinear Folding Wing Tips for Gust Loads Alleviation,” Journal of Aircraft, Vol. 53, No. 5, 2016, pp. 1391-1399. Doi:10.2514/1.C033474.

[25] Dussart, G., Yusuf, S., and Lone, M., "Effect of wingtip morphing on the roll mode of a flexible aircraft," AIAA/ASCE/AHS/ASC Structures, Structural Dynamics, and Materials Conference, 2018, 2018. Doi:10.2514/6.2018-1683.

[26] Cheung, R., Castrichini, A., and Cooper, J., “Testing of Wing-Tip Spring Device for Gust Loads Alleviation,” 58th AIAA/ASCE/AHS/ASC Structures, Structural Dynamics, and Materials Conference, American Institute of Aeronautics and Astronautics, Reston, Virginia, 2017. Doi:10.2514/6.2017-0630.

[27] Castrichini, A., Hodigere Siddaramaiah, V., Calderon, D., Cooper, J., Wilson, T., and Lemmens, Y., "Preliminary Investigation of Use of Flexible Folding Wing-Tips for Static and Dynamic Loads Alleviation." Aeronautical Journal, Vol. 121, No. 1235, 2017, pp. 73-94.

[28] Pace, S., North American XB-70 Valkyrie, Aero, 1990. ISBN : 0830686207.

[29] Jenkins, D. R., and Landis, T., North American XB-70A Valkyrie, Specialty Press, 2002. ISBN : 1580070566.

[30] Ross, J., and Rogerson, D., "XB-70 technology advancements," Aircraft Prototype and Technology Demonstrator Symposium, American Institute of Aeronautics and Astronautics, Reston, Virigina, 1983. Doi:10.2514/6.1983-1048.

[31] Davies, P., North American XB-70 Valkyrie, 2018. ISBN : 1472825055, 9781472825056.

[32] Jenkins, J. R., DeAngelis, V., Friend, E., and Monaghan, R., "Flight Measurments of Canard Loads, Canard Buffeting, and Elevon and Wing-Tip Hinge Moments on the XB-70 Aircraft Including Comparions with Predictions," Tech. rep., NASA Langley, Washington D.C., 1969.

[33] Andrews, S., "Modelling and Simulation of Flexible Aircraft: Handling qualities and active load control," Ph.D. thesis, Cranfield University, 2011. 
[34] Dussart, G., Portapas, V., Pontillo, A., and Lone, M., "Flight Dynamic Modelling and Simulation of Large Flexible Aircraft," Flight Physics - Models, Techniques and Technologies, InTech, 2018. Doi:10.5772/intechopen.71050.

[35] Dussart, G., Lone, M., and O'Rourke, C., "Size Estimation Tools for Conventional Actuator System Prototyping in Aerospace," Design and Optimization for Adaptive Structures, San Diego, California, 2018.

\section{Appendix}

\section{A. Atmospheric Model}

The atmospheric model was built as follows.

For altitudes $h$ below $11 \mathrm{~km}$, air temperature $T$ is given by:

$$
T=T_{0}-(L \times h)
$$

where $T_{0}$ is the sea-level temperature $292 K^{\circ}$ and $L$ is the temperature drop lapse rate at $0.0065 K^{\circ} \cdot m^{-1}$. For altitudes $h$ above $11 \mathrm{~km}$, air temperature $T$ is given by:

$$
T=215 K^{\circ}
$$

Speed of sound $a_{s}$ is then given by :

$$
a_{s}=\sqrt{\gamma \times \frac{R}{M_{\text {air }}} \times T}
$$

where $\gamma$ is perfect gaz heat capacity ratio at $1.4, R$ is the gas constant at $8.3, M_{\text {air }}$ is the molar mass of dry air at 0.0289 $\mathrm{kg} . \mathrm{mol}^{-1}$. Air density $\rho$ for $h$ below $11 \mathrm{~km}$ is then obtained using:

$$
\rho=\rho_{0} \times\left(\frac{T}{T_{0}}\right)^{4.25588}
$$

where $\rho_{0}$ is the sea-level air density. On the other hand, air density is interpolated from stratosphere data charts if $h$ is above $11 \mathrm{~km}$, with values ranging respectively from $0.3639,0.0880,0.0132$ and $0.0020 \mathrm{~kg} . \mathrm{m}^{-} 3$ at $11,20,32,47 \mathrm{~km}$ respectively. Dynamic pressure can then be obtained using:

$$
\bar{q}=\frac{1}{2} \times \gamma \times \frac{\rho}{M_{\text {air }}} \times R \times T \times M^{2}
$$


2019-01-06

\section{In-flight folding wingtip system:} inspiration from the XB-70 Valkyrie

\section{Dussart, Gaétan X.}

AIAA

pÿGaétan Dussart, Mudassir Lone, Ciaran O Rourke and Thomas Wilson. In-flight folding wingtip system: inspiration from the XB-70 Valkyrie. Proceedings of the AIAA Scitech 2019 Forum, 7-11 January 2019, San Diego, CA, USA.

https://doi.org/10.2514/6.2019-1855

Downloaded from Cranfield Library Services E-Repository 